\title{
Correction to: Political Parties
}

\section{Correction to:}

Chapter 4 in: C. Kirkland, Classifying Elections in Britain, https://doi.org/10.1007/978-3-030-32556-5_4

In the original version of the book, the digits in Figure 4.1 were separated incorrectly. This has now been corrected, and the book and chapter have been updated accordingly.

Correct Figure 4.1:

\begin{tabular}{|c|c|c|c|c|c|c|}
\hline Party & Seats & Contested & Total Spending & England & Scotland & Wales \\
\hline Conservative & 306 & 631 & $£ 16,682,874$ & $£ 14,298,166$ & $£ 1,273,110$ & $£ 1,111,598$ \\
\hline Labour & 258 & 631 & $£ 8,009,483$ & $£ 6,516,412$ & $£ 967,904$ & $£ 525,116$ \\
\hline Lib Dem & 57 & 631 & $£ 4,787,595$ & $£ 3,987,035$ & $£ 470,619$ & $£ 329,941$ \\
\hline Scottish National & 6 & 59 & $£ 315,776$ & - & $£ 315,776$ & - \\
\hline Plaid Cymru & 3 & 40 & $£ 144,933$ & - & - & $£ 144,933$ \\
\hline Green & 1 & 335 & $£ 325,425$ & $£ 325,425$ & - & - \\
\hline
\end{tabular}

The updated version of this chapter can be found at https://doi.org/10.1007/978-3-030-32556-5_4

(C) The Author(s) 2020

C. Kirkland, Classifying Elections in Britain, https://doi.org/10.1007/978-3-030-32556-5_7 